\section{Challenges to implementing a National Health Information System in Cameroon: perspectives of stakeholders}

\author{
Emmanuel Ngwakongnwi, ${ }^{1}$ \\ Mary Bi Suh Atanga,2 Hude Quan ${ }^{3}$ \\ 'University of Calgary, Doha, Qatar; \\ 2Department of Nursing, Faculty of \\ Health Sciences, University of Bamenda, \\ Cameroon; ${ }^{3}$ Department of Community \\ Health Sciences, University of Calgary, \\ Alberta, Canada
}

\section{Abstract}

In the early 90 s, the Cameroon Ministry of Health implemented a National Health Information System (NHIS) based on a bottom-up approach of manually collecting and reporting health data. Little is known about the implementation and functioning of the NHIS. The purpose of this study was to assess the implementation of the NHIS by documenting experiences of individual stakeholders, and to suggest recommendations for improvement. We reviewed relevant documents and conducted face-to-face interviews $(\mathrm{N}=4)$ with individuals directly involved with data gathering, reporting and storage. Content analysis was used to analyze textual data. We found a stalled and inefficient NHIS characterized by general lack of personnel, a labor-intensive process, delay in reporting data, much reliance on field staff, and lack of incentives. A move to an electronic health information system without involving all stakeholders and adequately addressing the issues plaguing the current system is premature.

\section{Introduction}

The Republic of Cameroon has a total population of 19.5 million inhabitants. ${ }^{1}$ The health system in Cameroon can be described as a pluralistic system, characterized by multiple sources of financing and health care providers. ${ }^{2}$ The main financing bodies include government, public enterprises, foreign aid donors, private enterprises, households, faithbased missions, and non-governmental organizations; whereas providers are mostly government, independent private and faith-based hospitals. ${ }^{2}$ The coordination of health care services is centralized in the capital, with the Ministry of Health at the helm, represented by Regional Delegates of Health in the ten administrative Regions.
Like most African countries, Cameroon lacks an organized health information system at all levels of care. Health records (in the form of booklets or vaccination cards) are kept by individual patients with an exception of some faith-based hospitals. Birth registries are performed at local councils, census data is held by the National Institute of Statistics, meanwhile some specialist programs maintain admission and discharge registers of patients. ${ }^{3}$

Realizing its inability to produce essential health statistics for policy and decision-making, the Ministry of Public Health began work to develop a new data gathering system. A major milestone in this effort was the creation, in 1992, of a National Committee for the Development of a National Health Information System (Informant at Ministry of Health). The goal was to develop a system of data collection and reporting, to serve all decision makers from health center up to central ministry of health. Since creation, there is a paucity of literature on the implementation and functioning of the National Health Information System (NHIS). The objective of this study was to document experiences of individual stakeholders involved with the implementation of the NHIS.

\section{Materials and Methods}

We used stakeholder analysis, a policy analysis research tool particularly suitable for generating knowledge from a wide range of actors. ${ }^{4}$ Research ethics requirements of the University of Buea were used to guide this study. This involved providing stakeholders with an introductory letter including a summary of the proposed research and obtaining approval. We approached and recruited stakeholders at district, regional and national levels. These were employees of the ministry who could actively or passively influence decisionmaking and implementation of the NHIS. This included data entry clerk, District Health Officer, Regional Delegate of Health, and Head of Service, Health Information in the Ministry of Health. Planning and data gathering lasted 3 months, from December 2010 to February 2011.

Given available resources, we selected the North West Region for interviews, and subsequently interviewed a participant in the Ministry of Health for a national perspective. We conducted face-to-face interviews and reviewed some documents related to the NHIS. Four of five scheduled interviews were completed. Each stakeholder was asked to describe what they knew about the NHIS, including their role and experiences with data gathering and reporting. This method of inquiry, ${ }^{5}$ enabled stakeholders to describe their individual roles and experiences; thereby subjecting
Correspondence: Emmanuel Ngwakongnwi, P.0. Box 23133, Al Rayyan campus, Al Forousiya Road, Doha, Qatar.

Tel. +97444065239 .

E-mail: engwakon@ucalgary.ca

Key words: health information system, health records, stakeholder analysis, Cameroon, Africa.

Acknowledgements: Dr. Ngwakongnwi, is Research Officer at University of Calgary - Qatar, was supported by the Frederick Banting and Charles Best - Canadian Institutes of Health Research (CIHR) Doctoral Research Award. Travel overseas was supported by a Canadian Institutes of Health Research, Michael Smith Foreign Study Supplement (CIHR-MSFSS). Dr. Mary Atanga, is Senior Lecturer and Senior Nursing Officer at the University of Bamenda, Cameroon, supported by research attributable grants. At the time of this research, she held a similar role at University of Buea, Cameroon. Dr. Quan, is professor, Community health Sciences at University of Calgary. He was supported by Alberta Innovate - Health Solutions salary awards.

Conflict of interests: the authors declare no potential conflict of interests.

Received for publication: 18 January 2013.

Revision received: 28 January 2014.

Accepted for publication: 4 February 2014.

This work is licensed under a Creative Commons Attribution NonCommercial 3.0 License (CC BYNC 3.0).

(OCopyright E. Ngwakongnwi et al., 2014 Licensee PAGEPress, Italy

Journal of Public Health in Africa 2014; 5:322 doi:10.4081/jphia.2014.322

them to further probing around those experiences. Notes taken during the interviews were developed into textual data and the content analyzed. Emerging positions of stakeholders were summarized into themes, a starting point in reporting findings from qualitative studies. ${ }^{6}$ We used line by line coding and followed by selective coding (assigning categories to themes) to produce descriptive summaries of our data. ${ }^{5}$ Coding of textual data was done by one researcher and reviewed by a second. Finally, we grouped categories by themes and selected exemplars to illustrate positions of stakeholders.

\section{Results}

Overall, our analyses of interviews and review of documents revealed a stalled, ineffi- 
cient but structured system of data collection and reporting in place; characterized by poor staffing and funding, delays in reporting of data, lack of feedback, poorly conceived data collection form, often with translation errors and instructions on how to complete certain sections of the forms were in French. Three themes emerged from the analysis:

\section{Theme 1: process of data collection and reporting}

We found that data collection and reporting envisaged at two levels in the regions, as one participant recounted.

Health data is collected at two levels. Level one involves health centers and level two is at the district hospital. Data collection forms are assembled on a monthly basis at the district level (from health centers) where it is being synthesized and send to the Region. The Region in turn forwards the data to the ministry where it is processed and stored.

\section{Theme 2: issues impacting data collection and reporting}

\section{Lack of personnel}

District Health Officers are at the crossroads of the data collection process. Their primary responsibility is to check the quality of data coming from district hospitals and health centers, as well as supervise data entry and reporting. In explaining this process, one officer recounted.

We encounter major problems with this initiative (referring to the NHIS). One of the major problems is lack of personnel. For example - we have 13 health centers in the district, and together with the district hospital, it adds up to 14 data units. It is very laborious to collect and process data from all these units per month... covering 12 months in a year... so the anticipated process of collecting, synthesizing and reporting data does not flow as it should be.

\section{Labor-intensive process}

A data entry clerk assigned to each district is primarily responsible for data entry and generating reports. A clerk described the NHIS as follows.

We are supposed to receive forms from the different health centers every month... I do data entry, after which it is sent to the Regional office in Bamenda. However, this is a very tedious process (pointing to a stack of paper on the floor). You can see, to go through all those forms within a month when am alone is very demanding.

\section{Delay in reporting}

The clerk further identified late reporting as the greatest challenge.
What even renders my job more difficult is the fact that the reports from health centers are sometimes not sent on time. Some health centers forward their reports the following month when am supposed to have completed for the previous month. This makes my work to pile up.

\section{Reliance on field workers}

Data from Regions is assembled in the Department of Health Information, Ministry of Health, where it is used for service planning and supposedly for surveillance purposes. A participant in the ministry had this to say about NHIS.

The system does not work. The people in the field are not doing their job. They don't send the reports. Even when some do, it is never on time... look at the boxes behind you. It was just send by one Region for 2009/2010, meanwhile we are in 2011. It is not up to date.

\section{Lack of incentive}

With regards to what may be the cause of lateness in reporting, the informant in the ministry added: they are not motivated (referring to field staff in the Regions)... they say it was not budgeted along with their other duties so they are simply not motivated to take on the additional task... they want to work but they need financial motivation.

\section{Theme 3: improving the National Health Information System}

Diverse opinions on how to improve data collection and reporting emerged. To the data entry clerk, there was need for better coordination.

I think better coordination and follow-up will help. The health center staff has to report what they have, rather than waiting to complete each section of the form before forwarding to us. Also, we need more personnel to help with the data entry.

In contrast, the informant in the Ministry of Health identified electronic health records (EHR) as the way forward: we are launching an electronic portal in 2012 (described as systemed'abonnement in French). This is promising for the future.

Asked how this will be different from the current system and how the issues enumerated will be taken care of, he added: it will be electronic... It will allow for the management of health data. Synthesis will be done automatically. In this case there will be no misuse of human resources. It is a numerical library (bibliothequenumerique in French), it is already available. We just have to roll it out.

\section{Discussion}

This study illustrates challenges with the implementation of a national health information system in Cameroon. Drawing from stakeholder perspectives in 1 of 10 administrative regions, we found that the system is inefficient. The centralized management and decision making in the ministry of public health, places high expectations on regional delegates for the NHIS to operate. This top-down system of managing a bottom-up process of data collection and reporting lacked adequate resources and technical know-how to be effective. Yet, there were plans to roll-out a new EHR system; without a stakeholder consultation to fully understand issues plaguing the current system. Improving the Cameroon NHIS initiative would require addressing the issues identified in this study. For the NHIS initiative to be complete and nationally representative there is need to involve private and faith-based health care providers in the planning, implementation and use of data at all levels.

Our findings somewhat collaborate those of a pilot project to implement an EHR system in Cameroon that encountered a 50\% stakeholder drop-out among other challenges. ${ }^{7}$ Change in management staff, breakdown of computer hardware, and departure of most investigators characterized the pilot project. ${ }^{7}$ The difficulties associated with top-down implementation of systems highlighted in this study are not exclusive to Cameroon. Not adequately engaging stakeholders at a lower level of data collection can lead to poor valuation of the system. This was evidenced in Ethiopia where district health workers perceived data collection and reporting as simply a work requirement, imposed upon them by higher levels. ${ }^{8}$

Researchers have found that efforts to improve top-down implementation of a health record system require combining government direction with increased local autonomy. ${ }^{8}$ This approach requires identifying the information needs of each stakeholder and defining what needs to be shared at each level. Additionally, health system usability, computer skills and the system's fit with the organizational culture and processes has been suggested as key factors to a successful implementation of an EHR. ${ }^{9}$

It should be noted that the opinions of stakeholders from the North West Region, sampled for this study do not represent the entire country. Due to limited resources and time constraints, we were unable to sample all 10 regions. Thus, a major limitation of this study is the fact that we interviewed a small convenient sample in one Region. Second, we focused on the NHIS data collection process and have not evaluated quality of data. Nevertheless, our informant in the central ministry of health pro- 
vided a national perspective, which to the research team constitutes a significant strength to the methods and associated findings. A detailed stakeholder analysis of the NHIS involving all 10 Administrative Regions is needed to identify areas for improvement at all levels of data collection and reporting. Without this, the Ministry's plan to move to an electronic health record system could be premature.

\section{Conclusions}

In addition to birth registries and census data, we have determined that the Cameroon NHIS is a potential source of health data with broad coverage, but that needs significant improvement. A point for reflection is whether Cameroon, a country with constant power cuts, poorly organized health care system with a majority of personnel lacking computer skills, is ready for a move to an electronic health record system.

\section{References}

1. World Health Organization. Country statistics-Cameroon 2011. Available from: http://www.who.int/countries/cmr/en/ Accessed: October 20, 2011.

2. Ntangsi J. An analysis of health sector expenditures in Cameroon using a national health accounts framework. Available from: https://www.hsph.harvard.edu/takemi/files/2012/10/rp141.pdf Accessed: August 4, 2013.

3. Kengne AP, Djouogo CF, Dehayem MY, et al. Admission trends over 8 years for diabetic foot ulceration in a specialized diabetes unit in Cameroon. Int J Low Extrem Wounds 2009;8:180-6.

4. Brugha R, Varvasovszky Z. Stakeholder analysis: a review. Health Policy Plan 2000;15:239-46.

5. Sandelowski M. Whatever happened to qualitative description? Res Nurs Health 2005;23:334-40.

6. Bazeley P. Analysing qualitative data: more than 'identifying themes'. Malaysian J Qual Res 2009;2:6-22.

7. Kamadjeu RM, Tapang EM, Moluh RN. Designing and implementing an electronic health record system in primary care practice in sub-Saharan Africa: a case study from Cameroon. Inform Prim Care 2005;13:179-86.

8. Mengiste SA. Analysing the challenges of IS implementation in public health institutions of a developing country: the need for flexible strategies. J Health Inf Develop Countries 2010;4:1.

9. Shaw V. Health information system reform in South Africa: developing an essential data set. Bull World Health Organ 2005; 83:8. 